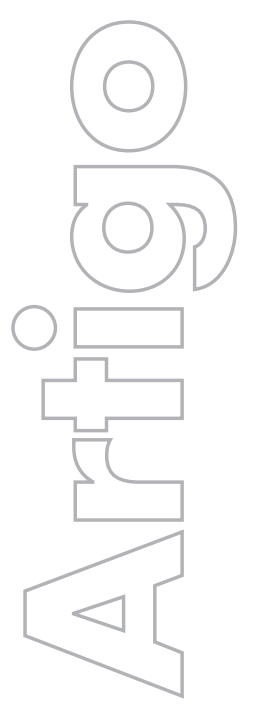

\title{
Caminhando em direção à metropolização do espaço
}

\author{
Alvaro Ferreira \\ PUC-Rio/UERJ
}

p. $441-450$

\section{revista}

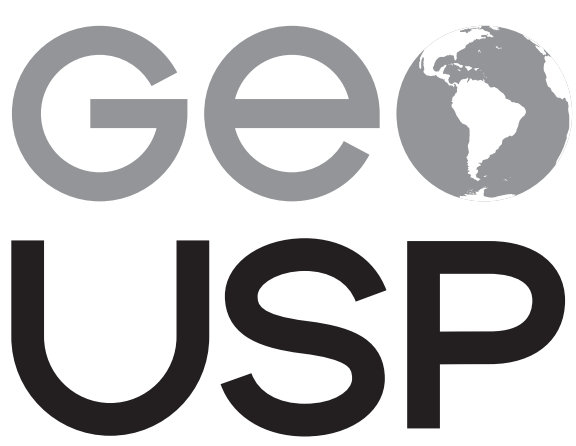

espaço e tempo

Volume $20 \cdot n^{\circ} 3(2016)$
Como citar este artigo:

FERREIRA, A. Caminhando em direção à metropolização do espaço. Geousp - Espaço e Tempo (Online), v. 20, n. 3, p. 441-450, mês. 2016. ISSN 2179-0892.

Disponível em: <http://www.revistas.usp.br/geousp/issue/ view/6465>. doi: http://dx.doi.org/10.11606/issn.2179-0892. geousp.2014.84539.

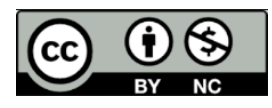

Este artigo está licenciado sob a Creative Commons Attribution 4.0 License. 


\title{
Caminhando em direção à metropolização do espaço
}

\section{Resumo}

Neste artigo, reconstruímos o caminho trilhado por Sandra Lencioni até chegar ao desenvolvimento de seu debate sobre a metropolização do espaço. Nessa trajetória, passamos pela relação urbano-rural, pela reestruturação urbano-industrial, pela centralização do capital e pela desconcentração da metrópole. É esse movimento que leva à metropolização do espaço. Depois, procurando apontar novas possibilidades de pesquisa a partir de sua construção teórica, discutimos as categorias cotidiano, espaço e ação, na tentativa de escapar da alienação.

Palavras-chave: Metropolização do espaço. Reestruturação urbana. Desconcentração. Cotidiano. Alienação.

\section{Moving towards the metropolization of space}

\begin{abstract}
The aim is the reconstruction of the path walked by Sandra Lencioni to reach the development of her debate on the metropolization of space. In this trajectory, we debated the urban-rural relations, urban-industrial restructuring, centralization of capital and deconcentration of metropolis. This is the movement she has done to get in metropolization of space. Later, trying to point out new possibilities of research from the cited theoretical framework, we approach everyday life, space and action categories in an effort to escape the alienation.
\end{abstract}

Keywords: Metropolization of space. Urban restructuring. Decentralization. Everyday life. Alienation.

\section{Introdução}

Ao pensarmos na trajetória intelectual de Sandra Lencioni e ao procurar o significado da palavra "intelectual", obtivemos as seguintes definições:

(a) Um intelectual é uma pessoa que usa o seu "intelecto" para estudar, refletir ou especular acerca de ideias, de modo que o uso de seu intelecto seja relevante social e coletivamente;

(b) o intelectual se define social e historicamente, segundo o papel das ideias numa dada sociedade; 
(c) Pessoa com grande interesse pelas coisas relacionadas à cultura, à literatura, à música e às artes.

Todas essas definições podem ser identificadas, mas os verdadeiros intelectuais têm em sua humanidade o seu grande diferencial e essa é uma das grandes qualidades que também nela encontramos.

O seu movimento intelectual passa por vários momentos até chegar no debate acerca da metropolização do espaço. Entretanto, creio que foi exatamente a sua trajetória de pesquisas que a fez chegar à metropolização.

Como sabemos, Sandra Lencioni foi reconhecidamente uma pesquisadora com ênfase em geografia regional, atuando principalmente em temas como teoria da região, metrópole e indústria.

Todavia, já em sua dissertação de mestrado, defendida em 1985, e intitulada Agricultura e urbanização. A intensificação do capital no campo e a transformação do urbano. Jardinópolis: o estudo de um lugar, já era possível observar que tinha a claramente a percepção da forte relação urbano-rural. Mais tarde, em 1991, em sua tese de doutorado intitulada Reestruturação urbano-industrial. Centralização do capital e desconcentração da Metrópole de São Paulo. A indústria têxtil, já começava a se edificar o que posteriormente traria como percurso analítico a metropolização do espaço. No decorrer dos anos de 1990, Sandra Lencioni percebe que a reestruturação industrial era, na verdade, urbano-industrial. Assim, mostra claramente que apesar de vivenciarmos a desconcentração industrial, simultaneamente, e cada vez mais, dava-se a centralização do capital, sendo a cidade de São Paulo fundamental nesse processo.

A reestruturação se dava em múltiplas dimensões e a flexibilização do trabalho cumpriu nessa fase importante papel. Nesse momento, terceirização e teletrabalho são fundamentais na transformação do cotidiano urbano e industrial.

$\bigcirc$ que estamos tentando deixar claro é que as inquietações intelectuais que alimentaram as pesquisas de Sandra Lencioni sempre estiveram interligadas e o processo que teve o papel de nexo aglutinador foi a metropolização do espaço. Mais recentemente suas pesquisas têm caminhado em direção à formação da Megarregião Rio de Janeiro-São Paulo, de certo modo um rebatimento espacial da metropolização do espaço.

Ao falar em metropolização do espaço, devemos remeter-nos de imediato a alguns fatos que darão sentido à análise. $\bigcirc$ primeiro é a consideração de que o fenômeno urbano, ligado à industrialização e à aglomeração (complexos urbano-industriais), marca das décadas anteriores à atual, vem dando lugar ao fenômeno metropolitano, ligado à desindustrialização, à desconcentração e à "explosão" da metrópole, isto é, à difusão dos códigos metropolitanos, num sentido amplo dessa imagem, num espaço muito além dos limites das regiões metropolitanas oficialmente delimitadas. $\bigcirc$ segundo fato é de que diversos outros processos espaciais estarão afetados por essa transformação de urbano para urbano-metropolitano ou, simplesmente, metropolitano. Especificamente estarão sendo referidos à gestão territorial e às relações urbano-rurais, processos percebidos como fortemente marcados pela metropolização do espaço.

A relação entre esses três processos deve ser vista numa perspectiva multiescalar, em que o primeiro subsome os dois outros, não só por alcançar a escala geral do território, mas principalmente por atribuir-lhes propriedades que, até recentemente, não possuíam ou eram fracamente manifestadas. Essas manifestações podem ser percebidas nas novas formas de ges- 
tão em que o lugar e as chamadas intervenções localizadas (e em parcerias público-privadas) ganham ênfase, em detrimento de intervenções mais centralizadas, com um papel mais direcionador do poder público; ao mesmo tempo, a antiga dicotomia rural-urbano, característica de divisões de trabalho anteriores à atual, é substituída por uma espacialidade hibrida, em que a dimensão metropolitana está presente no rural, alterando-o, principalmente nos comportamentos, fruto daquela difusão dos códigos metropolitanos (Ferreira; Rua; Mattos, 2015; Lencioni, 2015; Ferreira, 2015).

A metropolização incorpora algumas características anteriores e desenvolve outras. Trata-se, por exemplo, como nos lembrou Lencioni (2006), da grande intensidade de fluxos de pessoas, mercadorias e capitais, do crescimento das atividades de serviços e de cada vez maior demanda do trabalho imaterial, da concentração de atividades de gestão e administração, da cada vez maior utilização de tecnologias de informação e comunicação, da grande variedade de atividades econômicas com maior concentração de serviços de ordem superior, da exacerbação da associação entre o capital financeiro, promotores imobiliários e da indústria da construção, da produção de um modo de viver e de consumo que se espelha no perfil da metrópole (Lencioni, 2006, 2013; Ferreira, 2013a, 2014,; Rua, 2013).

A metropolização do espaço não se restringe às regiões metropolitanas, já que incorpora as cidades médias, as pequenas e o chamado "mundo" rural, hoje muito transformado e incorporando urbanidades. A dinâmica do processo de metropolização tem contribuído para a transformação do mercado do solo urbano, que passa por intensa valorização, elevando os preços a números nunca antes imaginados. Percebe-se, então, a importância da propriedade privada do solo como "condição indispensável à produção imobiliária formal", como lembra Lencioni (2013, p. 29). Esse aumento de preços faz com que as construtoras busquem áreas mais distantes para construção, incorporando novas áreas à lógica de mercado da metrópole, fato que obriga os moradores a realizarem grandes deslocamentos diariamente. Isso acaba por estender a área urbana indefinidamente, comprometendo inclusive o rural, integrado cada vez mais a esse processo especulativo, como se verá. Para falar desse espraiamento exacerbado da malha urbana, inúmeros autores passaram a referir-se à cidade difusa (Indovina, 1990; Capel, 2002, 2003), cidade dispersa (Monclús, 1998), cidade-região (Lencioni, 1994, 2006, 2013; Delgado, 1998; Sambricio, 1999; Téran Troyano, 1999, entre outros), cidade ilimitada (Nel·lo, 1998), megacidade, ${ }^{1}$ hipercidade (Corboz, 1995) etc.

As áreas de expansão e de investimentos nas cidades (e, já agora, também em algumas áreas do campo) acabam sendo definidas pelos proprietários fundiários, pelas construtoras e pelos promotores imobiliários. $O$ processo de metropolização tem, simultaneamente, levado ao adensamento de determinadas áreas, ao espraiamento da metrópole e às operações urbanas de renovação ou de revitalizações (como preferem alguns), que acabam por gerar forte gentrificação. Vivencia-se uma transformação que incorpora as dimensões econômica e social, em que grandes investimentos da esfera pública viabilizam a criação e/ou expansão das áreas centrais, articuladas à reprodução do capital financeiro, que produz segregação e apropriação desigual do espaço urbano.

1 Amplamente abordada por Sandra Lencioni na conferência de abertura do II Simpósio Internacional sobre Metropolização do Espaço, Gestão Territorial e Relações Urbano-Rurais. 
No início do século XXI, percebe-se que cada vez mais os governantes procuram construir uma marca para suas cidades; contudo, o "sucesso" de uma determinada cidade acaba provocando um movimento que objetiva copiar aquilo que teria dado certo, levando à homogeneização das formas-conteúdo, pois acreditam que assim atrairiam investidores. Contradição que aponta uma espécie de urbanização banalizada e consequentemente para a banalização do espaço (Ferreira, 2013b).

Muitas cidades têm seguido as definições de uma política empreendedorista, investindo em infraestrutura ligada às atividades turísticas, muitas vezes aproveitando-se de eventos internacionais, como em Barcelona (Jogos Olímpicos, 1992 e o Fórum de las Culturas, 2004), Lisboa (Expo' 98) ou Sevilha (Expo'92); o Rio de Janeiro vem seguindo o mesmo caminho: Jogos Pan-Americanos 2007, Copa do Mundo de Futebol 2014, Olimpíadas 2016.

Assim, agências multilaterais - BID, Banco Mundial, Pnud, Agência Habitat, entre outras - e consultores internacionais acabam construindo ideários e modelos que afirmam que as cidades devem comportar-se como empresas e adotar uma postura vencedora em um mundo que é visto como um mercado em que cidades competem entre si (Vainer, 2000). Assim, esse ideário defende que grandes projetos urbanos, recuperação de centros históricos, parcerias público-privadas e revitalizações fomentam a produtividade e competitividade da cidade, assegurando - graças à atração de investimentos, turistas e grandes eventos - uma inserção de sucesso no mundo globalizado. Além disso, surgem também como opção a criação de parques associados a grandes projetos imobiliários de condomínios de alto poder aquisitivo. A parte do tecido urbano avaliada pelos empreendedores como degradada ou habitada por grupos sociais de baixo poder aquisitivo, como velhas áreas fabris e armazéns em antigas zonas portuárias, tornam-se áreas potenciais para passar por refuncionalizações e para se transformarem em novos complexos de consumo. Nesse sentido, todo lugar acaba tornando-se uma cópia, em que surgem paisagens urbanas cada vez mais repetitivas que se descolam da própria realidade e história do lugar; é isso que se caracteriza como uma espécie de urbanização banalizada.

Grande parte dos projetos de revitalização que altera as características do lugar, criando novas fronteiras urbanas, acaba levando a processos de gentrificação, que de certo modo não deixa de ser uma forma de espoliação (Ferreira, 2013b).

Além disso, vivemos, agora, um momento marcado pela desconcentração do setor produtivo tradicional, pelo desenvolvimento de novos ramos da economia e pela centralização do capital na metrópole (Lencioni, 1991). Além disso, observamos a conformação de uma cidade difusa, que se expande desmesuradamente, dando novos conteúdos às antigas áreas rurais.

Retomando, é possível afirmar que o processo de metropolização imprime características metropolitanas ao espaço. Trata-se da alteração das estruturas pré-existentes, sendo esses espaços metrópoles ou não; ou seja, trata-se da transcendência das características metropolitanas a todo o espaço. Se o fenômeno urbano tomou o planeta, se se vive uma sociedade urbana (e não se refere aqui apenas ao domínio edificado), atualmente experimenta-se um processo de metropolização do espaço (Ferreira, 2014, 2013b).

Há também a incorporação de uma dimensão cultural. A esfera do consumo ganha proporções antes desconhecidas, alterando profundamente a cultura mercantil, que atinge todas as esferas da vida. Os hábitos culturais e os valores urbanos típicos da metrópole se difundem para além dela, chegando a todo o espaço, territorializado na mercadificação generalizada. 
A intensificação da capitalização do campo e a diversificação das atividades que lá se realizam, associadas ao desenvolvimento das tecnologias de comunicação e informação e também dos transportes aproximaram ainda mais as relações urbano-rurais. Assim, o processo de metropolização do espaço chega a áreas cada vez mais distantes, difundindo a cultura urbana, os valores urbanos, as normas e práticas sociais dominantes da metrópole. Se em determinado momento pudemos falar em urbanidades no rural, talvez agora tenhamos de aprofundar ainda mais esse debate, já que, atualmente, objetiva-se o desenvolvimento de condições metropolitanas que viabilizem ainda mais a reprodução do capital.

Não resta dúvida de que as estratégias de gestão territorial também são atingidas por esse processo, como podemos perceber. Ao discuti-lo, pensamos em políticas públicas que são bastante questionáveis em sua concepção, execução e em seus resultados; isso nos desafia a pensar em outras formas de gestão e planejamento; em como viabilizar formas de autogestão.

Entretanto, muito ainda temos que avançar. Mirando um pouco no final da década de 1980, e já livres do regime ditatorial militar, presenciamos forte mobilização popular, que acabou por promover o encontro entre as organizações dos movimentos populares, partidos políticos, entidades profissionais, sindicatos, $\mathrm{ONG}$ e pesquisadores universitários, o que posteriormente contribuiu para a construção do debate acerca da necessidade de uma reforma urbana.

Embora esse debate tenha sido intenso, resultou em apenas um capítulo com dois parágrafos em nossa nova constituição. Fato é que nos anos 2000 esse capítulo torna-se fortalecido pelo Estatuto da Cidade, que tem no Plano Diretor elemento fundamental.

Nos anos 1990, ainda sobre a recente onda de mobilização, duras críticas são feitas às formas anteriores de planejamento e gestão, inclusive muitos defendiam o fim do planejamento urbano e regional. Atacou-se o planejamento por ser rígido, burocrático, muitas vezes excessivamente ambicioso e incapaz de organizar verdadeiramente a estrutura urbana, já que o fazia privilegiando os interesses da elite.

Alguns autores propõem o que denominaram "planejamento urbano alternativo", que, ancorado na possibilidade de participação popular na produção do Plano Diretor, poderia mudar o modo de planejar a cidade. Evidentemente, a margem de manobra não era radical, pois falava da necessidade de priorizar a função social da propriedade, e não em sua negação.

planejamento urbano alternativo baseava-se na busca da justiça social, dessa maneira, preocupava-se com a melhor distribuição de investimentos públicos em infraestrutura, objetivando minimizar a segregação residencial. Mas a verdade é que da confecção da Nova Constituição Brasileira até a criação da lei que regulamenta os dois artigos acerca da reforma urbana (conhecida como Estatuto da Cidade), se passou muito tempo, algo em torno de 13 anos e isso acabou, de alguma forma, desmobilizando a população. Durante esse período, ganhou força uma forma de gestão que nega toda a lógica do planejamento urbano alternativo: o planejamento estratégico.

Com a elaboração de um Plano Estratégico, que tem origem na lógica empresarial e visa o lucro (e, nesse sentido, nada melhor do que convocar os empresários para fazê-lo) - as empresas têm planos estratégicos -, procura-se definir objetivos e políticas para conseguir acordos, coordenar as concessionárias privadas, dinamizar a economia e tornar as cidades 
competitivas em escala internacional. Contudo, essa lógica de planejamento e gestão não é facilmente desvelada, pois devido à propaganda e à toda uma produção de city marketing, o que se faz numa área restrita ganha ar de universal, ou seja, troca-se a parte pelo todo.

Parece-nos que a mercadificação da cidade, o city marketing e a implementação do empresariamento na governança da cidade trazem consequências danosas aos citadinos; estamos de acordo com o geógrafo inglês David Harvey (2005, p. 189), que acredita que o fortalecimento da competição de mercado entre as cidades produz impactos regressivos na distribuição de renda e a efemeridade dos benefícios trazidos por muitos projetos. Acredita ainda que "a concentração no espetáculo e na imagem, e não na essência dos problemas sociais e econômicos também pode se revelar deletéria em longo prazo, ainda que, muito facilmente, possam ser obtidos benefícios políticos".

Planos como esses têm produzido mundo afora projetos, revitalizações e obras espetaculares que se espelham em "modelos de sucesso", o que tem produzido, como mencionamos anteriormente, mais do mesmo, ou seja, uma espécie de urbanização banalizada e mais do que isso, uma banalização do espaço (Ferreira, 2013b).

É preciso, mais uma vez, pensar em novas formas de planejamento, baseadas no diálogo e na participação democrática, pois como diz Capel (2003, p. 241), "não podemos deixar que sejam os técnicos que nos dirijam, que nos ponham diante do fato consumado. Temos que impor o diálogo, tornar explícitas nossas opções e pôr os técnicos a nosso serviço". Aqui, embora não seja isso necessariamente o que Horacio Capel propõe, valeria a pena pensarmos na ideia de autogestão.

Em busca da verdadeira democracia, Marx (2005) acreditava que era necessário opor à burocracia a alternativa da autogestão, à autoridade do Estado a autonomia dos indivíduos. Evidentemente, chegar à verdadeira democracia, para Marx, significava caminhar para o desvanecimento do Estado (e, nesse caso, necessariamente para o fim de seu contraponto: a sociedade civil), o que levaria à constituição da comunidade.

Caminharíamos em direção a uma espécie de autogoverno, já que cada indivíduo governaria a si mesmo, assim, a comunidade como um todo se autogovernaria. Haveria funções sociais e administrativas que continuariam a ser exercidas, mas não mais como funções estatais. Marx (2012) as pensava como funções sociais análogas àquelas do Estado, mas não idênticas (nem coercitivas ou opressoras), pois se tornariam funções públicas. Nesse sentido, sendo funções públicas, as funções governamentais seriam transformadas em funções administrativas. Assim, para Marx, a autoridade estatal cederia lugar à autonomia individual, já que a repartição das funções gerais se tornaria tão rotineira, que não conferira nenhuma autoridade.

A proposta de Marx, verdadeiramente, talvez até por não ter sido totalmente elaborada e instrumentalizada, nunca foi posta em prática, mas não nos resta dúvida que é bastante empolgante e inquietadora. Pensar que os cidadãos passam a ter várias atividades para vivenciar o ser político em plenitude, e também que a atividade dos homens à semelhança do que ocorre com a autodeterminação e o autogoverno (de si mesmo e, então, de todos) é que explica a autogestão é no mínimo um convite à ação. Com isso alcançaríamos a possibilidade de conciliar as duas principais perspectivas na análise territorial: a mais funcional (que tem servido mais aos aparatos de controle) e a mais simbólica, que, se levada em consideração, oferece alternativas para formas de gestão mais democráticas e mais justas socialmente. 
Reforçando: a produção das cidades é realizada a partir de certas intencionalidades, que são materializadas para dar sustentação a um momento marcado pela metropolização do espaço. $\bigcirc$ século XXI trouxe com ele fatos novos, mas também permanências; processos novos, outros revisitados, e ainda outros que se constituem e se realizam a partir de processos anteriores.

A metropolização do espaço faz parte desse momento e contribui para profundas transformações de formas, estruturas e dinâmicas urbanas. Esse processo não exclui aquilo que o filósofo francês Henri Lefebvre denominou, no início da década de 1970, de urbanização completa da sociedade. Aliás, o processo de metropolização do espaço está para o momento atual, assim como a urbanização da sociedade estava para aquele momento. Por isso, a metropolização incorpora algumas características e desenvolve outras; e muitas vezes contribui para a negação do sentido do encontro, do estar junto. São inúmeros condomínios fechados, ruas fechadas, shopping centers, cercas elétricas, câmeras de vigilância... cada vez mais controle, e o que é pior: por vezes "desejado" e defendido pela população.

Por estar intimamente ligada ao cotidiano, a metropolização do espaço promove mudanças na própria maneira como vivemos na cidade.

O cotidiano, com toda a construção de uma história cultural que agrega normas e tradições, vivenciado na dimensão do espaço social, torna-se cada vez mais tensionado pela produção de um espaço abstrato, mas que produz uma espécie de abstração concreta. Sim, pois apesar de se tratar de um constructo mental, realiza-se a partir de uma realidade social concreta. Além disso, é possível perceber a tentativa de construção de um cotidiano programado, que atinge indistintamente a todos. É isso que leva Lefebvre $(1958,1968)$ a acreditar que a alienação adquire um sentido profundo, que acaba afastando o cotidiano de sua riqueza. Dissimula esse lugar da produção e da criação, recobrindo-o com a falsa pompa das ideologias.

A produção do espaço, em sua materialização agora dentro de uma lógica de metropolização, possibilita-nos pensar em uma dupla representação: a primeira encontra-se ligada à lógica do planejamento estratégico, que viabiliza projetos de "revitalização", de "reabilitação" ou, como preferem outros, de "renovação urbana", que têm apresentado como resultado a especulação imobiliária, a produção de uma urbanização banalizada e a gentrificação. É possível pensar no trinômio analítico homogeneização-fragmentação- hierarquização, na lógica do planejamento estratégico, a homogeneização na proposta de produção do espaço é visível. Por outro lado, outras representações sociais são possíveis e, por vezes, podem ser percebidas por manifestações espaciais que salientam insatisfações e inquietações com a lógica introjetada, com a ordem estabelecida. Em geral, ligam-se a sentimentos de indignação, mas também a outras possibilidades de pensar e viver na cidade. É no âmbito do vivido que podemos percebê-lo como fonte das contradições que invadem a cotidianidade e também podemos conceber novas possibilidades nos momentos de criação.

Mas, se nesse contexto, o cotidiano pode se apresentar alienante e alienador, é também a partir da percepção da alienação que podemos construir caminhos e possibilidades de transformação. Certeau (2012) pensa exatamente no homem ordinário, que escapa da conformação do cotidiano por meio da invenção, de astúcias sutis e de táticas de resistência. Assim, reapropria-se do espaço e de seu uso. Porque se o cotidiano incorpora e, muitas vezes, é 
controlado por um conjunto de normas estabelecidas (o que é terrivelmente empobrecedor), incorpora também a espontaneidade. Isso porque, como nos lembra o geógrafo Milton Santos (1996), o estudo do cotidiano sugere a possibilidade de trabalhar com três dimensões: corporeidade, individualidade e socialidade. A dimensão do corpo tem um caráter bastante objetivo, liga-se à capacidade de mobilidade, à forma como nos apresentamos e nos vemos; em se tratando da individualidade, o foco estaria na consciência de si, do lugar e também do mundo; e a socialidade diria respeito às relações entre os indivíduos. Com certeza é possível perceber que essas três dimensões estão totalmente interligadas; e quando as separamos, isso se justifica apenas para o momento da análise.

Como é no espaço que se materializam e se realizam as diferenças, é também por meio do espaço que podemos vislumbrar outras possibilidades, que podemos produzir novas formas que nos permitam imaginar e lutar por cidades justas.

Assim, quando reconstruímos a cotidianidade pela apropriação do espaço da cidade, é possível pensarmos na formação de movimentos que lutem pela emancipação e por sua transformação.

Ao falar da importância da cotidianidade, Milton Santos (1996, p. 257) acreditava que entender o cotidiano seria o caminho para compreender a relação entre espaço e movimentos sociais, entendendo a materialização das intencionalidades no espaço como "uma condição para a ação; uma estrutura de controle, um limite à ação; um convite à ação. Nada fazemos hoje que não seja a partir dos objetos que nos cercam", dizia ele.

Desafios. $\bigcirc$ cotidiano é, simultaneamente, o trivial e o pouco provável; a velocidade e o tempo lento; o lugar e o global. É no lugar, no dia a dia, que encontramos as respostas e também as dúvidas.

O espaço é fundamental para buscarmos a transformação, pois se queremos algo diferente, isso significa a produção de outra configuração do espaço; para mudar a vida, precisamos mudar também o espaço em sua forma-conteúdo.

Não podemos renegar o pequeno, o fugaz, até porque em muitos momentos surge como única resistência possível. Essa talvez seja a chance de nos contrapor à ação que se realiza "de cima para baixo", criando espaços de representação por meio da experiência construída em apreensões horizontais e cooperativas da vida cotidiana e coletiva. Talvez seja hora de valorizarmos mais o dissenso que o consenso, que é cada vez mais, de fato, produzido por uma mídia cada vez mais forte.

Outro do urbano é o homem comum, o homem simples, ou se quisermos pensar em Milton Santos (1996), o homem lento, que escapa dessa lógica, que mais que sobreviver, busca viver, porque resiste. Ele tenta se reinventar criativamente, cria táticas de resistência por meio da apropriação do espaço. Entretanto, não podemos esquecer que para cada pensamento revolucionário, surge um contrarrevolucionário, que a ideologia hegemônica tenta sempre neutralizar o desvendamento da verdadeira dimensão da lógica alienadora dominante.

É preciso considerar uma inversão de perspectiva para construção de um anticondicionamento, para escapar do cotidiano programado. Aqui, vale recordar o filósofo belga Raoul Vaneigem (2002) quando, de maneira provocadora, afirma que precisamos de uma tática lúdica: "o jogo da subversão, o desvio (détournement)". A inversão de perspectiva consagraria a vitória de um conjunto de relações humanas baseadas na participação, na comunicação e na realização, configurando a consciência da necessidade de uma revolução total. 
Quando Marx pensou na revolução, ela esteve sempre amparada na constituição do humano, então não é possível falar em revolução sem entendê-la como o ato de apropriação das condições de vida pela comunidade em nome das possibilidades do gênero humano.

São muitos os desafios, e a trajetória intelectual de Sandra Lencioni nos ajuda a seguir em frente... e a acreditar que é possível...

\section{Referências}

CAPEL, H. La Cosmópolis y la ciudad. Barcelona: Ediciones del Serbal, 2003.

La morfología de las ciudades: sociedad, cultura y paisaje urbano. Barcelona: Ediciones del Serbal, 2002. v. 1.

CERTEAU, M. A invenção do cotidiano: 1. Artes de fazer. 18. ed. Petrópolis-RJ: Vozes, 2012.

CORBOZ, A. L'ipercittá. Urbanistica. n. 103, 1995.

DELGADO, J. Ciudad-región y transporte en el México Central. México: Unam, 1998.

FERREIRA, A. Metropolização do espaço, cotidiano e ação: uma contribuição teórico-metodológica. In: FERREIRA, A.; RUA, J.; MATTOS, R. C. (Org.). Desafios da metropolização do espaço. Rio de Janeiro: Consequência, 2015. p. 69-84.

Metropolização do espaço, tensões e resistências: entre espaços de controle e controle do espaço. Scripta Nova - Revista Electrónica de Geografía y Ciencias Sociales, v. XVIII, n. 493, 1 nov. 2014.

A cidade no século XXI: segregação e banalização do espaço. 2. ed. Rio de Janeiro: Consequência, 2013b.

A imagem virtual transformada em paisagem e o desejo de esconder as tensões do espaço: por que falar em agentes, atores e mobilizações? In: FERREIRA, A.; RUA, J.; MARAFON, G. J.; SILVA, A. C. P. (Org.). Metropolização do espaço: gestão territorial e relações urbano-rurais. Rio de Janeiro: Consequência, 2013a. p. 53-74.

; RUA, J.; MATTOS, R. C. Metropolização do espaço, gestão territorial e relações urbano-rurais: processos e dinâmica - uma introdução. In: FERREIRA, A.; RUA, J.; MATTOS, R. C. (Org.). Desafios da metropolização do espaço. Rio de Janeiro: Consequência, 2015. p. 15-32.

HARVEY, D. A produção capitalista do espaço. São Paulo: Annablume, 2005.

INDOVINA, F. La cittá difusa. Veneza: Daest, 1990.

LEFEBVRE, H. La vie quotidienne dans le monde moderne. Paris: Gallimard, 1968.

Critique de la vie quotidienne I: Introduction. Paris: L'Arche Editeur, 1958.

LENCIONI, S. Metropolização do espaço e a constituição de megarregiões. In: FERREIRA, A.; RUA, J.; MATTOS, R. C. (Org.). Desafios da metropolização do espaço. Rio de Janeiro: Consequência, 2015. p. 35-68. 
- Metropolização do espaço: processos e dinâmicas. In: FERREIRA, A.; RUA, J.; MARAFON, G. J.; SILVA, A. C. P. (Org.). Metropolização do espaço: gestão territorial e relações urbano-rurais. Rio de Janeiro: Consequência, 2013. p. 17-34.

. Reconhecendo metrópoles: sociedade e território. In: SILVA, C. A. et al. (Org.). Metrópole: governo, sociedade e território. Rio de Janeiro: DPEA, 2006.

- Reestruturação urbano-industrial no estado de São Paulo: a região da metrópole desconcentrada. In: SANTOS, M.; SOUZA, M. A.; SILVEIRA, M. L. (Org.). Território: globalização e fragmentação. São Paulo: Hucitec, 1994. p. 54-61.

Reestruturação urbano-industrial: centralização do capital e desconcentração da metrópole de São Paulo, a indústria têxtil. Tese (Doutorado em Geografia Humana) - Faculdade de Filosofia, Letras e Ciências Humanas, Universidade de São Paulo, São Paulo, 1991.

MARX, K. Crítica do programa de Gotta. São Paulo: Boitempo, 2012.

Crítica da filosofia do direito de Hegel. São Paulo: Boitempo, 2005.

MONCLÚS, F. J. Estrategias urbanísticas y crecimiento suburbano en las ciudades españolas: el caso de Barcelona. In: MONCLÚS, F. J. (Org.). La ciudad dispersa. Barcelona: Centro de Cultura Contemporánea de Barcelona, 1998. p. 371-385.

NEL LO $O$. Los confines de la ciudad sin confines: estructura urbana y límites administrativos en la ciudad difusa. In: MONCLÚS, F. J. (Org.). La ciudad dispersa. Barcelona: Centro de Cultura Contemporánea de Barcelona, 1998. p. 35-57.

RUA, J. $\bigcirc$ urbano no rural fluminense e o preço da terra: continuando a reflexão. In: FERREIRA, A.; RUA, J.; MARAFON, G. J.; SILVA, A. C. P. (Org.). Metropolização do espaço: gestão territorial e relações urbano-rurais. Rio de Janeiro: Consequência, 2013. p. 383-408.

SAMBRICIO, C. Madrid, ciudad-región: de la Ciudad Ilustrada a la primera mitad del siglo XX. Madrid: Ayuntamiento de Madrid /Ministerio de Fomento, 1999. v. 1.

SANTOS, M. A natureza do espaço: técnica e tempo, razão e emoção. São Paulo: Hucitec, 1996.

TÉRANTROYANO, F. Madrid, ciudad-región: entre la ciudad y el territorio en la segunda mitad del siglo XX. Madrid: Madrid, 1999. v. 2.

VAINER, C. B. Pátria, empresa e mercadoria: notas sobre a estratégia discursiva do Planejamento Estratégico Urbano. In: ARANTES, O.; VAINER, C.; MARICATO, E. (Org.). A cidade do pensamento único: desmanchando consensos. Petrópolis: Vozes, 2000.

VANEIGEM, R. A arte de viver para as novas gerações. São Paulo: Conrad, 2002. 